\title{
Religion and Health During the COVID-19 Pandemic
}

\author{
Curtis W. Hart ${ }^{1} \cdot$ Harold G. Koenig ${ }^{2,3,4,5}$
}

Published online: 15 May 2020

(c) Springer Science+Business Media, LLC, part of Springer Nature 2020

\begin{abstract}
A Special Section of a future issue of the Journal of Religion and Health will be devoted to religion and health during the COVID-19 pandemic. The present time is like no other in most of our lifetimes. We are all facing an uncertain future, with little control over what happens next. The only certainty for many now is their religious faith, which is a rock that they are now needing to hold onto. Indeed, religious faith will likely make an important difference in how many make it through this challenging time in our nation's and world's history. This topic-how religion can make a difference, what religious people and communities are doing in response, and how religious people can stay healthy-is the focus of the Special Section. The authors include a wide range of experts in religion-health research, opinion leaders in this field, and those on the front lines - clergy and health professionals-grappling with the care of patients in our hospitals and clinics, including COVID-19 patients. Here is a brief overview of a sample of articles that will be appearing in this Special Section:
\end{abstract}

- Tyler VanderWeele, an endowed professor at the Harvard School of Public Health and Director of the Human Flourishing Program there, examines the cost that suspending religious activities may have on mental and physical health, how individuals can compensate, and what it means to "love thy neighbor" during an infectious disease pandemic.

Harold G. Koenig

harold.koenig@duke.edu

Curtis W. Hart

cuh9001@med.cornell.edu

1 Division of Medical Ethics, Departments of Medicine and Psychiatry, Weill Cornell Medicine, New York City, NY, USA

2 Department of Psychiatry \& Behavioral Sciences, Department of Medicine, Duke University Medical Center, Durham, NC, USA

3 Department of Medicine, King Abdulaziz University, Jeddah, Saudi Arabia

4 School of Public Health, Ningxia Medical University, Yinchuan, People's Republic of China

5 Shiraz University of Medical Sciences, Shiraz, Iran 
- Professor Jeff Levin from Baylor University examines the role of the faith community in responding to the SARS-CoV-2 outbreak, either as part of the solution or part of the problem, and provides a background on the COVID-19 pandemic, presenting his viewpoint as an epidemiologist who is well-familiarized with this situation.

- Psychiatrist Harold G. Koenig from Duke University Health Systems describes the impact of anxiety/fear on the immune system, how religious involvement may enhance immune function and resilience against the coronavirus, and how individuals can stay mentally, socially, spiritually, and physically healthy during this COVID-19 pandemic.

- Professor Francesco Chirico from Milan, Italy, who is the official medical doctor of the Italian State Police and professor of the Post-graduate Specialization of Occupational Health at Università Cattolica del Sacro Cuore, Rome, and his wife, Professsor Gabriella Nucera, who is employed as an emergency medical doctor at Fatebenefratelli Sacco Hospital in Milan, tell their experience on the frontlines treating patients during the COVID-19 pandemic in Italy.

- Dr. Dan Hale, Director of Healthy Community Partnerships at Johns Hopkins Bayview Medical Center in Baltimore, and his colleagues describe the process of transitioning a pastoral visitation and care for laypersons program from addressing the needs of those with chronic illness to those battling the coronavirus.

- Psychologist Barry Hong at Washington University in St. Louis and Professor Paul Handal from St Louis University present a reflective paper on theological and psychological themes/perspectives related to the COVID-19 pandemic, including mistrust that many have of science and the medical community and misbeliefs about the biological advantage of African Americans (belief that they can't get the virus). They also comment on the religious community's response and what should happen post-pandemic.

- Professor Stephen Modell and Associate Dean Sharon Kardia from the School of Public Health at the University of Michigan provide a report and reflection on the role that religious communities in Detroit, and surrounding areas are currently playing and will continue to play in dealing with this pandemic.

- Psychology professor Sarah Weinberger-Litman at Marymount Manhattan College in New York City writes about anxiety during the early quarantine period in this city, providing a quantitative report and analysis of those in the communities first affected by the coronavirus outbreak and its spread into Westchester County and the Bronx.

- Father Joshua Genig, an Eastern Orthodox priest and $5^{\text {th }}$ year chaplain resident at the University of Michigan Medical Center, explores the role of mystery in the care of patients suffering from COVID-19, paying special attention to the disparity between modern and postmodern approaches to mystery and how medical and spiritual care have often been conducted in the vein of the former. He also discusses the opportunity that postmodern and millennial medical clinicians serving on the frontlines of this pandemic now have to return to a more ancient manner of understanding humanity, illness, suffering, and even death.

- Social scientist Steven Pirutinsky and colleagues examine the impact that the coronavirus has had on the American Orthodox Jewish community. In their 
quantitative study of 419 American Orthodox Jews, they explore the relationships between exposure, religiosity, and mental health during the COVID-19 pandemic.

- Professor of Public Health Stephanie St. Pierre reviews a book by physician Matt McCarthy, Superbugs: The Race to Stop an Epidemic. This book takes us up to the edge of the pandemic and is prescient in nature, anticipating our current state of affairs. This important book adds context to the background of what COVID19 has now made real in our everyday lives.

These articles will be published individually online as each is ready, and all will appear in the Special Section in a future issue of the journal. We look forward to additional manuscript submissions. Please contact Editor-in-Chief Hart (e-mail cuh9001@med.cornell.edu) with your manuscript proposal for this special section. If approved, please submit your manuscript via https://editorialmanager.com/jorh/. Please consult the submission guidelines on the journal homepage (www.springer. com/10943).

In conclusion, it has been said that "journalism is the first draft of history," a cliché perhaps, though good to keep in mind at this time. This Special Section will provide a "second draft of history" in the form of literate essays that combine research and narrative. Together, these papers have enough substance for readers of the Journal to intentionally take time to review. They are an overview of the religious community's responses to COVID-19 that can be read individually or as a group and may be useful as an academic or clinical resource both now and in the future. 